\title{
Is Low-Dose-Rate Endorectal Brachytherapy a New Treatment Method for Locally Advanced Distal Rectal Cancer?
}

\author{
Seung Hyuk Baik \\ Division of Colon and Rectal Surgery, Department of Surgery, Yonsei University College of Medicine, Seoul, Korea
}

See Article on Page 123-130

In the treatment of locally advanced rectal cancer, preoperative chemoradiotherapy improved the rate of local recurrence after surgery and anal sphincter preservation [1]. Because it resulted in down-staging of tumors and changes of histologic characteristics, it is now regarded as the standard treatment in the patients with stages II-III advanced rectal cancer [2]. Conventional preoperative chemoradiotherapy used a dose of $50.4 \mathrm{~Gy}$ with concurrent chemotherapy before surgery. However, there were concerns because of increased risks of radiation toxicity and morbidity after external beam irradiation.

In these regards, the endocavitary brachytherapy technique was introduced to reduce radiation-related toxicity and to down-stage the primary resectable rectal cancer [3]. Endorectal brachytherapy has advantages because it can deliver a high dose of radiation around the tumor target and spare normal tissues such as small bowel, urinary bladder and skin. Vuong et al. [4] reported that a high dose rate of endorectal brachytherapy as preoperative chemoradiotherapy can reduce local recurrence with favorable toxicity compared with external mean radiotherapy.

This article reported the phase-II clinical outcomes of low-doserate endorectal brachytherapy as a boost to neoadjuvant chemoradiotherapy compared with conventional preoperative chemoradiotherapy for the treatment of locally advanced rectal cancer [5]. It was demonstrated that endorectal brachytherapy showed a more decreased rate of pathologic tumor size and tumor stage. In

Correspondence to: Seung Hyuk Baik, M.D.

Division of Colon and Rectal Surgery, Department of Surgery, Yonsei

University College of Medicine, 50-1 Yonsei-ro, Seodaemun-gu, 03722, Korea

Tel: +82-2-2019-3378, Fax: +82-2-3462-5994

E-mail:whitenoja@yuhs.ac

(C) 2015 The Korean Society of Coloproctology

This is an open-access article distributed under the terms of the Creative Commons Attribution NonCommercial License (http://creativecommons.org/licenses/by-nc/3.0) which permits unrestricted noncommercial use, distribution, and reproduction in any medium, provided the original work is properly cited. addition, there was a higher rate of pathologic complete response and acceptable toxicity after endorectal brachytherapy compared with concurrent neoadjuvant chemoradiatherapy only. Although this study evaluated only 34 patients as a phase-II clinical trial, the results are meaningful to suggest the efficacy and safety of lowdose rate endorectal brachytherapy for the treatment of locally advanced distal rectal cancer. However, according to a recent report for the long-term results of a randomized trial for brachytherapy for locally advanced rectal cancer, there were no benefits of 5-year overall survival and progression-free survival after brachytherapy in spite of increased pathologic tumor regression [6]. The results of this study might decrease justification of the use of brachytherapy for locally advanced rectal cancer in terms of oncologic outcomes. Moreover, brachytherapy is a complicated treatment procedure compared to conventional preoperative chemoradiotherapy. Without a doubt, the present study needs a further large-scale randomized phase III study to assure oncologic benefits compared to conventional chemoradiotherapy or highdose-rate endorectal brachytherapy as a boost to conventional neoadjuvant chemoradiotherapy. However, in terms of dose reduction of brachytherapy in this study, I am looking forward to seeing not only oncologic outcomes but also better short-term clinical outcomes in the future investigation of the present study.

\section{CONFLICT OF INTEREST}

No potential conflict of interest relevant to this article was reported.

\section{REFERENCES}

1. Bosset JF, Collette L, Calais G, Mineur L, Maingon P, RadosevicJelic L, et al. Chemotherapy with preoperative radiotherapy in rectal cancer. N Engl J Med 2006;355:1114-23.

2. Bosset JF, Calais G, Mineur L, Maingon P, Radosevic-Jelic L, Daban A, et al. Enhanced tumorocidal effect of chemotherapy with preoperative radiotherapy for rectal cancer: preliminary results- 
EORTC 22921. J Clin Oncol 2005;23:5620-7.

3. Smith JA, Wild AT, Singhi A, Raman SP, Qiu H, Kumar R, et al. Clinicopathologic comparison of high-dose-rate endorectal brachytherapy versus conventional chemoradiotherapy in the neoadjuvant setting for resectable stages II and III low rectal cancer. Int J Surg Oncol 2012;2012:406568.

4. Vuong T, Devic S, Podgorsak E. High dose rate endorectal brachytherapy as a neoadjuvant treatment for patients with resectable rectal cancer. Clin Oncol (R Coll Radiol) 2007;19:701-5.
5. Omidvari S, Zohourinia S, Ansari M, Ghahramani L, Zare-Bandamiri M, Mosalaei A, et al. Efficacy and safety of low-dose-rate endorectal brachytherapy as a boost to neoadjuvant chemoradiation in the treatment of locally advanced distal rectal cancer: a phase-II clinical trial. Ann Coloproctol. 2015;30:123-30.

6. Appelt AL, Vogelius IR, Ploen J, Rafaelsen SR, Lindebjerg J, Havelund BM, et al. Long-term results of a randomized trial in locally advanced rectal cancer: no benefit from adding a brachytherapy boost. Int J Radiat Oncol Biol Phys 2014;90:110-8. 